\title{
Maintenance and Reinforcement Design of Relics Steel Arch Bridge
}

\author{
Shuai Yuan ${ }^{1, a}$, Weizhen Chen ${ }^{1, b}$ \\ ${ }^{1}$ Department of bridge engineering Tongji University, Shanghai, China \\ a378309934@qq.com, btongji_bridge611@126.com
}

\begin{abstract}
Keywords: Relics Bridge, Steel Arch Bridge, Arch rib and suspender Reinforcement, Orthotropic Bridge Deck Optimization.
\end{abstract}

\begin{abstract}
Many domestic steel structure urban bridges built in the last century have been maintained and strengthened in succession because of reaching their design working life. These old bridges have the triple function of historical culture, human landscape and transportation. The maintenance and reinforcement design method must be fully considered to maximize the protection of the old structure integrity so that they can continue exerting their function and role. Therefore, this paper, taking a relics steel arch bridge in Zhejiang Province as the research background, mainly introduces the optimization and reinforcement design of orthotropic bridge deck system, arch ribs and suspenders. After strengthening the bridge can meet the requirements of the design specification and the protection of cultural relics. It has a certain reference value for the reinforcement design of similar bridges.
\end{abstract}

\section{Introduction}

At present, many bridges has reached the design working life. The maintenance and strengthening of old bridges have gradually become significant for the bridge construction. Although our country has just got through the peak period of bridge construction, there are a great number of built bridges which will face a lot of repair and reinforcement works[1]. Among them, some steel structure urban bridges built in the early 20th century have been maintained and strengthened in succession. For example, the Tianjin Jiefang Bridge built in 1927 was repaired and strengthened by the points of "restoring the old as the old" and "movable bridge recovery" in 2006. Now the bridge can not only meet the demands of the traffic in present but also ensure the security and reliability to open in the conditions under 5 grade wind[2]. The Shanghai Waibaidu Bridge built in 1907 was also completely overhauled in 2009 with the basic principle of "restoring the old as the old" and the protection scheme of moving the upper steel truss by ship and repairing and constructing the sub-pier structure in situ, letting the bridge structure be thoroughly updated under the premise of keeping its historical features, which had ensured the continuous safe use[3]. The Guangzhou Haizhu Bridge built in 1929 was damaged severely in decades of war. The middle hole, bridge deck and steel truss structure were respectively reinforced in 1950, 1974 and 1996[4]. And in 2012, the bridge was rush repaired again with the same principle of "restoring the old as the old", making Haizhu Bridge keep its historical features and safe operation. Now the overhaul engineering of Shanghai Zhejiang Lu Bridge built in 1906 is also busy being carried out. These bridges have some common characteristics: built in the early 20th century, steel structure bridge, experiencing the baptism of war, cultural relics bridge, having the triple function of historical culture, human landscape and transportation. Their reinforcement designs also pay attention to protect the integrity of the original old structure, adhering to the principle of "restoring the old as the old". Therefore, the reinforcement design of this kind of relics steel bridge should focus on the 
maximum preservation of the value of cultural relics.

This paper, taking a relics steel arch bridge in Zhejiang Province as the background, mainly studies the maintenance and reinforcement methods of relics steel arch bridge, considering the optimization design of orthotropic bridge deck system and the replacement and flitch reinforcement of damaged components of arch rib and suspender, getting some corresponding conclusions.

\section{Engineering Situation}

The steel arch bridge built in 1936 was recommended to be Zhejiang provincial cultural relics protection construction in 2005. It is a single-span half-through three-hinged steel arch bridge with a span of $97.552 \mathrm{~m}$. The general arrangement drawing is shown in figure 1 . The main rise-span ratio is $1 / 6.6$ and the arch axis is a circle-arc line with a radius of $86.349 \mathrm{~m}$. The original width of bridge was $20.17 \mathrm{~m}$, widened to $25 \mathrm{~m}$ in the overhaul in 1994 . There are a total of 12 suspenders on the bridge whose center distance is $7.925 \mathrm{~m}$ except few intermediate suspenders. The arch rib is box section which consists of a roof, two webs, a middle diaphragm, a bottom plate, and several connection angles. The suspender is H-section made up of a web and four angles, which are respectively riveted on arch rib and beam on both sides. The bridge deck system, which originally consisted of vertical and horizontal steel beams and concrete slabs, was changed to orthotropic steel bridge deck system in the overhaul in 1994. The substructure is made up of two hollow box abutments and some inclined pine piles.

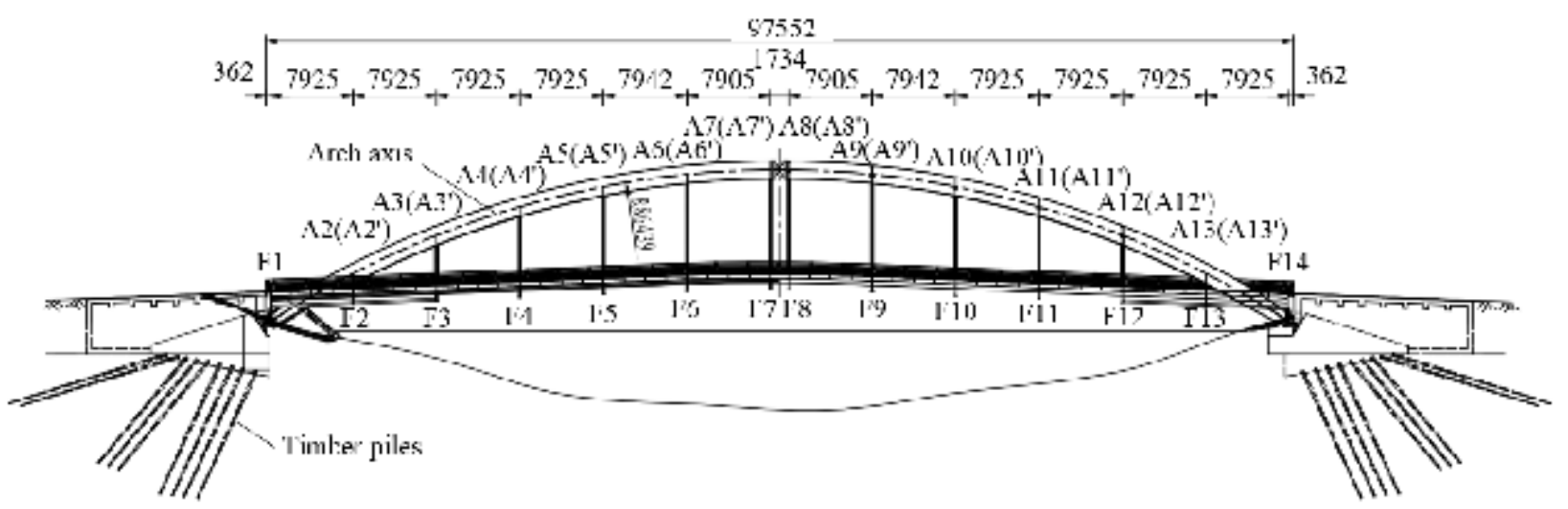

Fig.1 The general arrangement elevation drawing of status quo

The bridge was bombarded many times in the war, which led to the deflection of arch ribs and the serious damage of two hollow box abutments. The bullet marks on arch ribs, suspenders, portal-frames, wind bracings and vertical and horizontal beams can be seen everywhere. In following years operating, although the bridge had been repaired several times, it was still deteriorating because of the factors such as load and atmospheric corrosion, etc. In 1994, in order to meet the increasing traffic demand, there was a major overhaul of the bridge, which included adding new steel brackets to widen the bridge for pedestrians and non-motor vehicles traffic, transforming the original concrete bridge deck to orthotropic steel bridge deck and coating skewbacks with concretes to protect the arch hinges from water erosion.

Recently, due to the promotion of river navigation level and the frequency of tidal change, the clearance under the bridge was deficiency and the ship collision accidents repeatedly occurred. Soon afterward, the bridge was detected to ensure the safety, including detection of various diseases of the upper structure, ultrasonic inspection of key nodes and members, form and 
position measurement of the arch ring, the traffic investigation, etc. The detection results showed that: Firstly, the arch rib existed many craters. Many parts of the coating had failed. The sealing measure of the deck and arch had been invalid. There was a large amount of water in arch rib box leading to serious corrosion, as shown in figure 2(a). Secondly, many suspenders' surface corrosion was serious. The anticorrosion paints mostly degenerated, as shown in figure 2(b). Thirdly, the bottom of some bridge brackets had been collided by boat repeatedly leading to obvious deformation and damage. Many longitudinal beams had the diseases of cracking and sealing-off, as shown in figure 2(c). Fourthly, a large area of bridge deck and many stiffening ribs were fractured, causing waterproof function failure of bridge deck. Many plates of bridge deck were corroded seriously, as shown in figure $2(d)$.

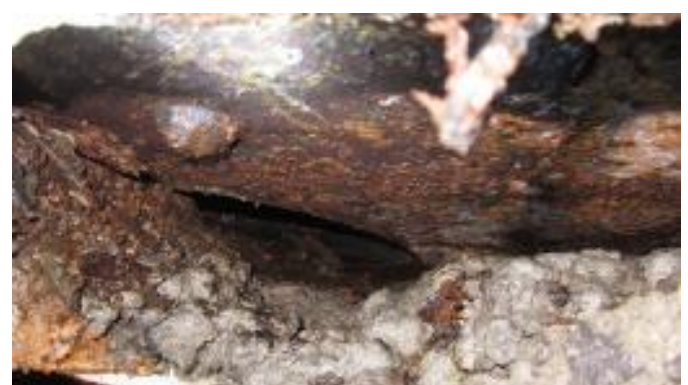

(a) Serious corrosion of arch rib box

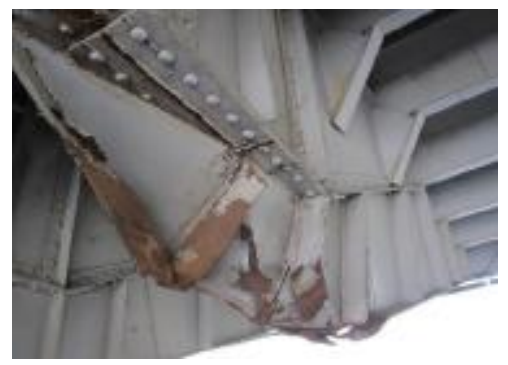

(c) Deformation and damage of bracket

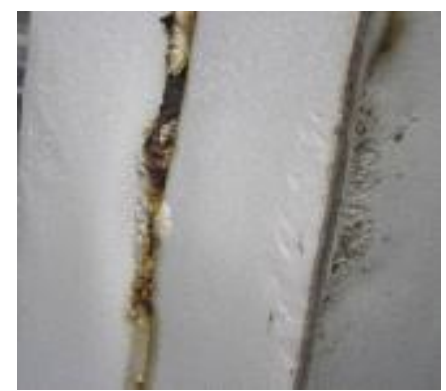

(b) Serious corrosion of suspenders' surface

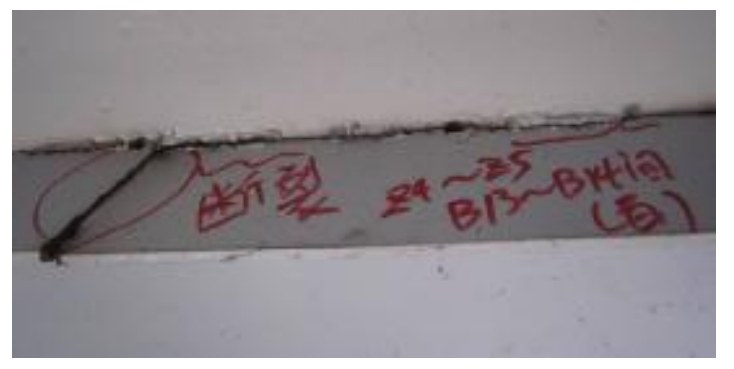

(d) Open stiffening ribs fracture

Fig.2 Bridge diseases figure

According to the disease conditions, the competent units started the bridge maintenance and reinforcement project, trying to extend the service life of bridge on the basis of protecting value of cultural relics so as to make it not only continue to take ground transportation but also keep the style and exert its functions of history and culture.

\section{Reinforcement design}

The design principle is "restoring the old as the old, on the basis of protecting value of cultural relics, consideration to transportation function". According to this principle, based on the city-B designing load[5], by the finite element modeling analysis calculation, the reinforcement design scheme is determined. New reinforcement material adopt Q345qd steel. In addition, the old steel structure was built in 1936, whose Sulphur content and Phosphorus content are high. The connection must be riveting or bolting without welding otherwise thermal embrittlement phenomenon[6] will occur. Therefore, in order to guarantee the strength of the steel structure, the connection between old components should be riveting, between new components and old components also must be riveting and between new components can be welding to facilitate construction.

Reinforcement of bridge deck system. As shown in figure 3(a) and 3(b), the bridge deck 
system which originally consisted of steel vertical and horizontal beams and concrete decks, was changed to orthotropic steel bridge deck system in the overhaul in 1994. At the same time in order to widen the bridge deck, the bridge bracket was reformed with a new component around the old bracket. But the clearance under the bridge was limited and the river navigation level and water level were promoted, leading to multiple ship collision accidents.

In this reinforcement design the bracket must be reconstruct to reduce the beam height and increase the clearance to avoid ship collision accidents. As shown in figure 3(c), to protect the integrity of the original structure, all of the old vertical and horizontal beams will be retained. Among them, some serious deformation components will be repaired with the method of mechanical correction. The reinforcement brackets of 1994 will be replaced to new I-section brackets, whose web thickness is $12 \mathrm{~mm}$ as the old cross beams' web thickness so that they can splice each other. The thickness of lower flange in the horizontal section is $30 \mathrm{~mm}$ and in the oblique section is $16 \mathrm{~mm}$. The box edge stringer will be replaced according to the size of the original $402 \mathrm{~mm} * 476 \mathrm{~mm}$.

The open stiffeners of orthotropic steel bridge deck reinforced in 1994 didn't have enough strength and there were many welding defects, resulting in serious crack of bridge decks and vertical and horizontal beams. In this reinforcement design all of the reinforcement decks and beams in 1994 must be replaced. As shown in figure 3(c), new bridge deck is $14 \mathrm{~mm}$ thickness. The new cross beam is located at the top of the old, still using I-section. According to the size of the old cross beam, the web of new cross beam is $12 \mathrm{~mm}$ thickness and the lower flange is $16 \mathrm{~mm}$ thickness which will be riveted with the upper flange of the old cross beam. The new longitudinal beam is also located at the top of the old longitudinal beam. The web of new longitudinal beam is $12 \mathrm{~mm}$ thickness and the lower flange is $30 \mathrm{~mm}$ thickness. There are three new I-section cross beams between each two main cross beams. The web thickness is $10 \mathrm{~mm}$ and the lower flange thickness is $16 \mathrm{~mm}$. All of the open stiffening ribs will be replaced to the close U-shaped stiffening ribs whose mechanical properties are more excellent[7]. According to the construction requirements[8], the close stiffeners size is: the height is $250 \mathrm{~mm}$, the thickness is $8 \mathrm{~mm}$ and the distance between two ribs is $267 \mathrm{~mm}$.

As shown in figure 3(b), the reinforcement brackets of 1994 were welded with the angles riveted on old brackets. This connection didn't have enough intensity, causing serious tear of the old bracket in ship collision accidents(see figure 2(c)). In this reinforcement design the new bracket web will be riveted with the old cross beam web and the new cross beam web by splice plates, as shown in figure 3(c), to ensure enough strength of the connection between new bracket and cross beam. 


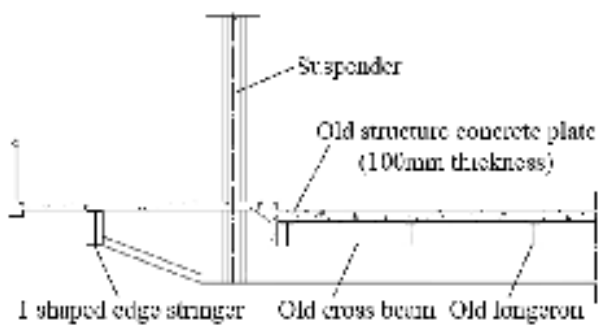

a) old bridge deck system

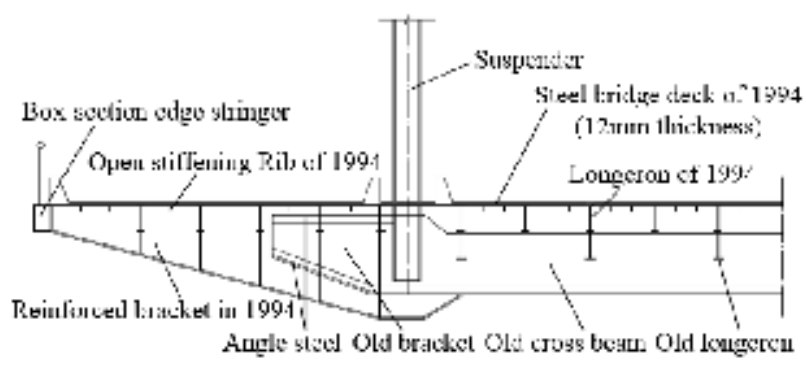

b) reinforcement bridge deck system in 1994

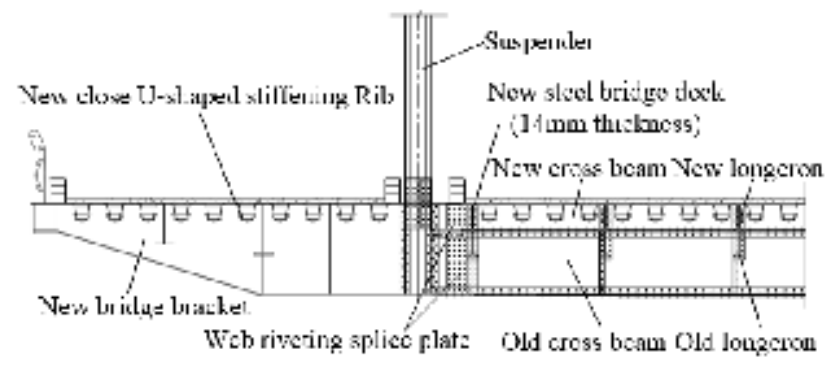

c) new bridge deck system

Fig.3 The schematic diagram of bridge deck system reinforcement

Reinforcement of bridge arch rib. In the reinforcement design of deck system, changing the open stiffeners to close U-shaped stiffeners, thickening the middle bridge decks, adding new cross beams and so on have increased the overall weight of bridge deck system by nearly $60 \%$. Therefore, the arch ribs must be reinforced otherwise the bearing capacity will not be able to meet the relevant calculation requirements in the current design criteria[9] and the bridge will damage.

The general section of the old arch rib is shown in figure 4(a). In this reinforcement design, to maintain the integrity of the old structure, the roofs, webs, and some undamaged connection angles of the old arch ribs should be retained and internally reinforced with steel flitches. Only the internal damaged members can be replaced so as not to change the old structure appearance. Firstly, each arch rib web will be reinforced with three pieces of steel flitches at the top, bottom and central axis in order to strengthen the top and the bottom, which are the key positions of the maximal bending stress, and the central axis, which is the key position of the maximal shearing stress. The riveting between flitches and webs should use the original rivet holes as much as possible. Secondly, the internal middle diaphragms, bottom plates and their flitches will be replaced to new components with the same size. Thirdly, after the demolition of middle diaphragms and bottom plates, if the connection angles of the roofs and the webs are removed, the old arch rib will be overall scattered and difficult to restructuring. So the reinforcement of roofs should not adopt the flitches inside the roof plates, but add new longitudinal diaphragms at the top of the arch rib with angles riveted on the web. The new reinforcement arch rib section is shown in figure 4(b). The dark regions are all new reinforcement components. The thickness of each flitch of the web is $20 \mathrm{~mm}$ and the length of the flitch at the central axis is $300 \mathrm{~mm}$. The upper longitudinal diaphragm is $30 \mathrm{~mm}$ thickness, whose angles are $160 * 160 * 14 \mathrm{~mm}$. The middle diaphragm is $10 \mathrm{~mm}$ thickness as original, whose angles also use the size of $70 * 70 * 10 \mathrm{~mm}$. 


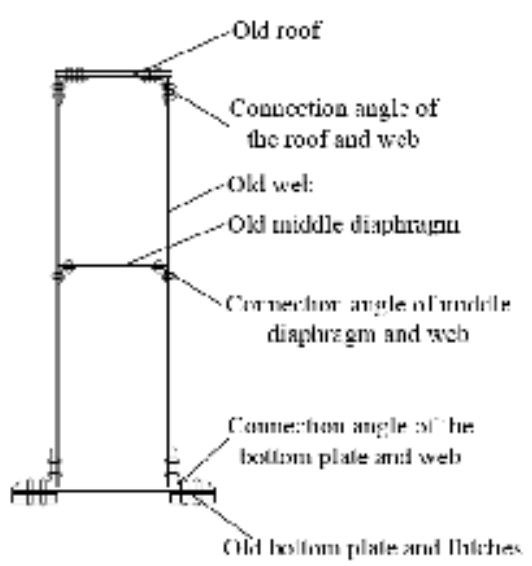

(a)Old section of arch rib

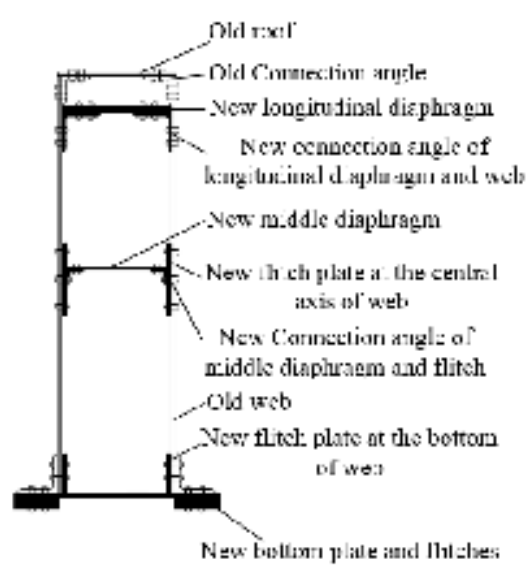

(b)New section of arch rib

Fig.4 The schematic diagram of arch rib reinforcement

Reinforcement of portal-frame and suspender. The portal-frames and the suspenders don't exist serious damages that endanger the safety of the structure. And the bearing capacity can meet the relevant calculation requirements in the current design criteria[9]. To maintain the integrity of the old structure, in this reinforcement design, the portal-frames will be reused after straightening and derusting, and reconstructed in situ according to the original riveting. The undamaged angles and webs of the suspenders will be retained and the serious corrosion damaged angles and webs will be replaced with the original size.

\section{Conclusions}

This paper, taking a relics steel arch bridge as the research object, has mainly introduced the bridge reinforcement design scheme of the upper structure. Through the optimization and transformation of bridge deck system and the replacement and flitch reinforcement of damaged components of the arch ribs and suspenders, the bridge can satisfy the operating requirements of the design specification, which has attained the expected purpose of reinforcement design. The reinforcement scheme have adhered the concept of "restoring the old as the old", trying not to change the original structure appearance and protecting the value of cultural relics in maximum. Now the bridge will continue keeping the original appearance and exerting its history, culture and traffic function.

\section{References}

[1] WZ Chen, et al: Assessment and Strengthening of Steel Truss Bridge, Science press, Beijing, 2012.

[2] ZX Zhang, et al: Repairing and Strengthening of Tianjin Jiefang Bridge, Tianjin Construction Science, 2007, (3): 41-44

[3] GP Yue, et al: Design of Protection Project of Ship-removal Repair of Waibaidu Bridge, Shanghai construction science and technology, 2009, (5): 1-5.

[4] Y. Zan, Main Construction Technology of Haizhu Bridge Reinforcement Project, Engineering construction and design, 2003, (5): 32-34.

[5] Shanghai Municipal Engineering Design Institute, Code for design of City Bridge 
(CJJ11-2011), China architecture \& building press, Beijing, 2011.

[6] ZY Shen, YJ Chen, YY Chen, Steel Structures, China architecture \& building press, Beijing, 2005.

[7] John W. Fisher, Fatigue and fracture in steel bridge: case studies, Wiley-Interscience publication, New York, 1984.

[8] China iron \& steel research institute group, Code for Design of Steel Structure (GB50017-2003), China architecture \& building press, Beijing, 2006.

[9] CCCC highway consultants CO., Ltd, Specifications for design of steel structure and timber highway bridges and culvers, China communications press, Beijing, 1986. 